\title{
High Temperature Water Gas Shift Catalysts with Alumina
}

\author{
Morris D. Argyle \\ mdargyle@byu.edu \\ Tiberiu Popa \\ Guoqing Xu \\ Thomas F. Barton
}

Follow this and additional works at: https://scholarsarchive.byu.edu/facpub

Part of the Chemical Engineering Commons

\section{Original Publication Citation}

T. Popa, G. Xu, T.F. Barton, M.D. Argyle, "High Temperature Water Gas Shift Catalysts with Alumina." Applied Catalysis A: General, 379, 15-23, 21. http://www.sciencedirect.com/science/ journal/92686X/379/1-2

\section{BYU ScholarsArchive Citation}

Argyle, Morris D.; Popa, Tiberiu; Xu, Guoqing; and Barton, Thomas F., "High Temperature Water Gas Shift Catalysts with Alumina" (2010). Faculty Publications. 101.

https://scholarsarchive.byu.edu/facpub/101 


\title{
High Temperature Water Gas Shift Catalysts with Alumina
}

\author{
Tiberiu Popa ${ }^{\mathrm{a}}$, Guoqing $\mathrm{Xu}^{\mathrm{a}}$, Thomas F. Barton ${ }^{\mathrm{b}}$, and Morris D. Argyle ${ }^{\mathrm{a}, \mathrm{C} *}$ \\ ${ }^{\mathrm{a}}$ Department of Chemical and Petroleum Engineering, University of Wyoming, \\ 1000 E. University Ave., Laramie, WY 82071, USA \\ ${ }^{\mathrm{b}}$ Western Research Institute, 365 N. $9^{\text {th }}$ Street, Laramie, WY 82072, USA \\ 'Current address: 350 CB, Brigham Young University, Provo, UT 84602.
}

\begin{abstract}
Alumina $\left(\mathrm{Al}_{2} \mathrm{O}_{3}\right)$ was added as a component of conventional iron oxide based high temperature water gas shift (WGS) catalysts. The catalysts contained Fe-Al-Cr-Cu$\mathrm{O}$ and were synthesized by coprecipitation. A series of catalysts were prepared with 5 to $50 \mathrm{wt} \% \mathrm{Al}_{2} \mathrm{O}_{3}, 8 \mathrm{wt} \% \mathrm{Cr}_{2} \mathrm{O}_{3}, 4 \mathrm{wt} \% \mathrm{CuO}$, and the balance $\mathrm{Fe}_{2} \mathrm{O}_{3}$. One catalyst was prepared in which the chromia was replaced by alumina. All of the catalysts were compared to a reference WGS catalyst (88 wt\% $\mathrm{FeO}_{\mathrm{x}}, 8 \mathrm{wt} \% \mathrm{Cr}_{2} \mathrm{O}_{3}$, and $4 \mathrm{wt} \% \mathrm{CuO}$ ) with no alumina. The catalysts were characterized using temperature programmed reduction (TPR), surface area analysis using nitrogen physisorption, and scanning electron microscopy (SEM) with compositional analysis. The catalysts were also tested kinetically under WGS conditions.

Addition of 10 to $15 \mathrm{wt} \%$ alumina increased the catalyst activity and thermal stability, with approximately $15 \mathrm{wt} \%$ alumina addition being optimum, as this catalyst produced a reaction rate (normalized per mass) 74\% higher than the reference catalyst. The effect of alumina addition was greater than the surface area increase alone, which suggests that alumina alters the activity of the iron oxide domains, likely through an increase in reducibility, as shown by the TPR results. This synergistic effect was only observed when both alumina and chromia were present. Alumina alone (as a replacement for chromia) was not as an effective stabilizer as chromia. Although both the aluminacontaining catalyst (without chromia) and the reference with chromia had similar initial surface areas ( $\left.160 \mathrm{~m}^{2} / \mathrm{g}\right)$, the alumina-containing catalyst retained only $74 \%$ as much surface area after reaction. Results from the catalysts with $50 \mathrm{wt} \%$ alumina suggest that the loss of catalytic activity is due also to the formation of aluminates.
\end{abstract}

Keywords: Alumina, thermal stability, HT water gas shift catalyst

* Corresponding author 


\section{Introduction}

The water gas shift (WGS) reaction is one of the main industrial methods for the production of hydrogen. Typically, the carbon monoxide (CO) reactant is derived from the synthesis gas (syngas) obtained from various carbonaceous materials [1].

$$
\mathrm{CO}+\mathrm{H}_{2} \mathrm{O} \leftrightarrow \mathrm{CO}_{2}+\mathrm{H}_{2} \quad \Delta \mathrm{H}^{\circ}{ }_{298}=-41.1 \mathrm{~kJ} / \mathrm{mol}
$$

As shown above, WGS is a moderately exothermic, reversible reaction. Thus, the equilibrium constant increases at lower reaction temperatures, which is the reason the industrial reaction is operated in two stages. The initial stage involves high temperature (HT) conversion $\left(300-500^{\circ} \mathrm{C}\right)$ with an iron oxide/chromia spinel catalyst [1, 2, 3, 4], which reduces the exit CO concentration to about 3 vol\% $[1,9]$. Conversion of the majority of the remaining CO is carried out in a second low temperature (LT) process stage $\left(210-250^{\circ} \mathrm{C}\right)$ using a high activity $\mathrm{Cu} / \mathrm{ZnO} / \mathrm{Al}_{2} \mathrm{O}_{3}$ catalyst $[1,3,4,5]$.

Iron oxide based WGS catalysts were discovered in 1909 by BASF researchers [1]. The active component of the catalyst is magnetite $\left(\mathrm{Fe}_{3} \mathrm{O}_{4}\right)[1,6,7,8]$. However, the thermal stability of magnetite is low, resulting in rapid sintering at the $300-500^{\circ} \mathrm{C}$ reaction temperature. Therefore, a refractory oxide $\left(\mathrm{Cr}_{2} \mathrm{O}_{3}\right)$ was added to increase the thermal stability by slowing the rate of sintering. Although catalysts with $14 \mathrm{wt} \% \mathrm{Cr}_{2} \mathrm{O}_{3}$ were more resistant to sintering, $8 \mathrm{wt} \% \mathrm{Cr}_{2} \mathrm{O}_{3}$ produced a more active catalyst [8]. The mechanism of chromia's effect was a matter of debate: whether chromia prevents sintering as crystals that physically block the movement of iron [7] or by entering the magnetite structure as solid solution that modifies the characteristics of the material [8]. Using physical characterization techniques, the latter hypothesis was demonstrated 
because crystalline chromia is not observed below $14 \mathrm{wt} \% \mathrm{Cr}_{2} \mathrm{O}_{3}$ [8]. Copper was later incorporated into the industrial catalyst formulations because its addition as $\mathrm{CuO}$ increases the catalytic activity. Current industrial WGS catalysts include 2-4 wt\% CuO. During reduction to activate the catalysts, metallic $\mathrm{Cu}$ leaches from the structure and forms individual crystallites on the surface of magnetite, which sinter into larger crystals if the inital $\mathrm{CuO}$ content is increased above $4 \mathrm{wt} \%$ and also increases the overall sintering of the catalysts $[1,9,10]$. Again, copper's role in HT-WGS is still the subject of debate. Some researchers propose that the effective component is metallic $\mathrm{Cu}$, which acts in the same way as in the $\mathrm{Cu} / \mathrm{ZnO} / \mathrm{Al}_{2} \mathrm{O}_{3}$ LT-WGS catalyst [1], while others suggest that $\mathrm{Cu}$ in the magnetite structure modifies the electronic properties of the standard $\mathrm{Fe}_{3} \mathrm{O}_{4} / \mathrm{Cr}_{2} \mathrm{O}_{3}$ catalyst [6].

The mechanism of the HT-WGS catalyst is regenerative, with electron exchange between $\mathrm{Fe}^{2+}$ and $\mathrm{Fe}^{3+}$ from the octahedral sites of the magnetite inverse spinel structure, as shown by Mossbauer spectroscopy [11], which ensures the redox coupling required by the regenerative mechanism [12, 13].

Although HT-WGS catalysts can function 10 years [8] by increasing the initial quantity of the catalyst in industrial reactors, typical iron based WGS catalysts are used for 2-5 years. The loss of catalytic activity is largely due to sintering $[1,8]$, as opposed to other causes of deactivation (from poisoning, coking, etc.). Therefore, a method to increase the resistance to sintering is desirable. Most of the loss in catalytic activity occurs in the first $150 \mathrm{~h}$ of operation, followed by a much lower rate of deactivation over extended periods of several years [1, 8]. 
The catalysts prepared in this study include alumina because alumina has been reported to enhance thermal stability $[9,14]$. The effects on thermal stability and reaction rate with by alumina addition to iron oxide based HT-WGS catalysts will be described in this paper.

\section{Experimental}

\subsection{Catalyst preparation}

Appropriate amounts of $\mathrm{Fe}\left(\mathrm{NO}_{3}\right)_{3} \bullet 9 \mathrm{H}_{2} \mathrm{O}(99.99 \%$, Sigma-Aldrich),

$\mathrm{Cu}\left(\mathrm{NO}_{3}\right)_{2} \cdot 2.5 \mathrm{H}_{2} \mathrm{O}\left(99.99 \%\right.$, Sigma-Aldrich), $\mathrm{Cr}\left(\mathrm{NO}_{3}\right)_{3} \cdot 9 \mathrm{H}_{2} \mathrm{O}$ (>98.5\%, Fisher Scientific)

and $\mathrm{Al}\left(\mathrm{NO}_{3}\right)_{3} \cdot 9 \mathrm{H}_{2} \mathrm{O}(>98.5 \%$, Sigma-Aldrich) were dissolved in deionized water and stirred for about 30 minutes. Sodium hydroxide (97.6\%, Fisher Scientific) or ammonium hydroxide (30\% $\mathrm{NH}_{4} \mathrm{OH}, \mathrm{J}$. T. Baker Chemical) solution was used to increase the $\mathrm{pH}$ from acidic (2-3) to basic to form a precipitate in a procedure described by Rhodes [1].

As shown in Table 1, which lists the solubility product constants of the precursor metal hydroxides, the solubilities vary by many orders of magnitude, with iron(III) having the lowest solubility product constant and $\mathrm{Cu}(\mathrm{II})$ the highest. In order to minimize segregation of these precipitates during titration, a precalculated quantity of sodium hydroxide (97.6\%, Fisher Scientific) or ammonium hydroxide $\left(30 \% \mathrm{NH}_{4} \mathrm{OH}\right.$, J. T. Baker Chemical) in solution was added in less than 5 seconds to the solution of nitrates to reach a $\mathrm{pH}$ of approximately 8 . During and after titration, the solution was stirred (Corning stirrer/hot plate). The $\mathrm{pH}$ was monitored using a microprocessor $\mathrm{pH}$ meter (Hanna Instruments $\mathrm{pH}$ 211). The catalysts titrated with $\mathrm{NH}_{4} \mathrm{OH}$ required copper addition during a separate aqueous incipient wetness impregnation step because the 
copper cations form ammonium complexes that do not precipitate with the rest of the precursors.

Because the precipitate was difficult to filter if left at this intermediate $\mathrm{pH}$ value, the $\mathrm{pH}$ was increased to 11 in less than 1 minute by titration. After titration, the catalyst was aged for $1 \mathrm{~h}$ with stirring (870 rpm). The brown precipitate was then vacuum filtered and rinsed several times with deionized water to remove soluble anions and cations.

The material was dried for $16 \mathrm{~h}$ (overnight) in an oven at $90^{\circ} \mathrm{C}$ and then calcined in air using an electronic oven (Applied Test Systems 3210 furnace) at $300^{\circ} \mathrm{C}$ for $5 \mathrm{~h}$ to decompose the hydroxides to oxides.

These catalysts were named as function of their weight percentage of oxide content $\left(\mathrm{Fe}_{2} \mathrm{O}_{3}, \mathrm{Cr}_{2} \mathrm{O}_{3}, \mathrm{CuO}, \mathrm{Al}_{2} \mathrm{O}_{3}\right)$ expected after calcination, based on the nominal amounts of precursors used in their preparation. For example, 73Fe-15Al-8Cr-4Cu was prepared to contain 73 wt $\% \mathrm{Fe}_{2} \mathrm{O}_{3}, 15$ wt $\% \mathrm{Al}_{2} \mathrm{O}_{3}, 8$ wt $\% \mathrm{Cr}_{2} \mathrm{O}_{3}$ and 4 wt $\% \mathrm{CuO}$ after calcination in air.

After calcination, the catalysts were crushed and sieved to retain particles with sizes between 125-250 $\mu \mathrm{m}$. Finer particles were pelletized at $34 \mathrm{MPa}$ (using a Carver press) in a $13 \mathrm{~mm}$ evacuable pellet die, crushed, and sieved again until all catalysts were in the desired size range.

The following catalysts were synthesized based on this procedure:

- 88Fe-8Cr-4Cu, used as a reference, prepared using $\mathrm{NaOH}$ as precipitation agent;

- 88Fe-8Cr-4Cu, using $\mathrm{NH}_{4} \mathrm{OH}$ as precipitation agent;

- 88Fe-8Al-4Cu, where chromia in the reference catalyst was replaced by alumina, prepared using $\mathrm{NaOH}$ as precipitation agent; 
- 88Fe-8Al-4Cu, prepared using $\mathrm{NH}_{4} \mathrm{OH}$ as precipitation agent;

- catalysts with increasing amounts of alumina, designated as $83 \mathrm{Fe}-5 \mathrm{Al}-8 \mathrm{Cr}-4 \mathrm{Cu}$, 78Fe-10Al-8Cr-4Cu, 73Fe-15Al-8Cr-4Cu, and 68Fe-20Al-8Cr-4Cu, prepared using $\mathrm{NaOH}$ as precipitation agent;

- 43Fe-50Al-5Cr-2Cu, prepared using $\mathrm{NaOH}$ as precipitation agent;

- 43Fe-50Al-5Cr-2Cu(m), obtained by mechanical mixture of the 73Fe-15Al-8Cr-

4Cu catalyst with high surface area $\gamma$-alumina (Alfa-Aesar, 99.9\%, $220 \mathrm{~m}^{2} / \mathrm{g}$ ) to produce a physical mixture with a total of $50 \mathrm{wt} \% \mathrm{Al}_{2} \mathrm{O}_{3}$.

\subsection{BET surface area}

Nitrogen physisorption experiments to obtain BET surface area [5] measurements were performed (Micromeritics ASAP 2010).

\subsection{Temperature Programmed Reduction (TPR)}

Temperature programmed reduction (TPR) studies were conducted in a flow microreactor using about $0.05 \mathrm{~g}$ ( $50 \mathrm{mg}$ ) catalyst for each sample. Before the TPR, the catalysts were dehydrated and oxidized for $1 \mathrm{~h}$ at $300^{\circ} \mathrm{C}$ in $20 \mathrm{sccm}$ (standard cubic centimeter/minute) of flowing air (US Welding) and $\mathrm{N}_{2}$ (Ultra High Purity, UHP, US Welding) mixtures with $5 \% \mathrm{O}_{2}$. The temperature was then decreased to room temperature under flowing nitrogen to prevent moisture from reentering catalyst. Then, 5 vol $\% \mathrm{H}_{2}$ in $\mathrm{N}_{2}$, (total flow $=40 \mathrm{sccm}$ ), was used to reduce the catalyst. The temperature was increased from room temperature $\left(\sim 25^{\circ} \mathrm{C}\right)$ to $800^{\circ} \mathrm{C}$ at a rate of $10^{\circ} \mathrm{C} / \mathrm{min}$. The hydrogen concentration in the effluent gas was monitored in real time using a quadrupole mass spectrometer (MKS Cirrus 100).

\subsection{EPMA/SEM}


Scanning electron microscopy (SEM) with electron probe micro-analyzer (EPMA) were used to obtain chemical compositions of the samples. The EPMA measurements were performed on a JEOL, JXA-8900R WD/ED combined microanalyzer. All of the samples were screened to retain 125-250 $\mu$ m diameter particles, as used for the kinetic experiments. The samples for EPMA were prepared as thin sections representative of the near surface of the catalysts.

\subsection{Kinetic evaluation}

The WGS kinetic experiments used the following gases: CO (UHP, Airgas), $\mathrm{N}_{2}$ (99.998\%, US Welding), $\mathrm{H}_{2}$ (UHP, Messer MG Industries), He (UHP, US Welding), air (H.P., US Welding), and $\mathrm{CO}_{2}$ (99.99\%, US Welding).

The flow rate of each gas was controlled via a mass flow controller (Porter Instruments series 201). Water was supplied by a high pressure pump (Scientific Systems-Lab Alliance Series 1) and vaporized in a coil type vaporizer wrapped in heating tapes. The stainless steel tubing before and after the reactor was heat traced and included thermocouples to monitor the temperature. During all experiments, all heat-traced tubes were maintained at a temperature above the dew point of water to avoid water condensation. The reactor was a $7 \mathrm{~mm}$ internal diameter quartz U-tube with a porous frit to support the catalyst. The reactor pressure used for these experiments was atmospheric. Following the reactor, the water vapor was condensed in a water-cooled condenser. The remaining product gases were treated in a desiccant-filled water trap and analyzed by a gas chromatograph (Agilent 6890N) equipped with a packed column (Supelco Carboxen 1000) to separate the $\mathrm{H}_{2}, \mathrm{CO}, \mathrm{N}_{2}$, and $\mathrm{CO}_{2}$, and a thermal conductivity detector (TCD) to measure the concentrations of the gases. 
The catalysts were reduced in situ for $2 \mathrm{~h}$ at $400^{\circ} \mathrm{C}$ in a $125 \mathrm{sccm}$ flow of $20 \%$ hydrogen, $30 \%$ steam, and $50 \% \mathrm{~N}_{2}$. Under these reduction conditions, $\mathrm{Fe}_{3} \mathrm{O}_{4}$ is the stable phase [2, 8].

Each catalyst ( $0.1 \mathrm{~g})$ was tested kinetically under water gas shift conditions of 3:1 $\mathrm{H}_{2} \mathrm{O}$ :CO volume ratio at a total molar flow rate $\left(\mathrm{H}_{2} \mathrm{O}\right.$ and $\left.\mathrm{CO}\right)$ of $1.24 \mathrm{x} \cdot 10^{-4} \mathrm{~mol} / \mathrm{s}$. All were tested for at least $24 \mathrm{~h}$. Most were subjected to extended tests for $100 \mathrm{~h}$ at $400^{\circ} \mathrm{C}$, followed immediately by $16 \mathrm{~h}$ at $500^{\circ} \mathrm{C}$ to accelerate sintering and to simulate a longer use. The temperature was decreased again to $400^{\circ} \mathrm{C}$ for comparison with the initial activity. A few experiments were conducted at lower $\mathrm{H}_{2} \mathrm{O}: \mathrm{CO}$ molar ratios of 2 . Experiments to determine activation energies were conducted at reaction temperatures between $350^{\circ} \mathrm{C}$ and $425^{\circ} \mathrm{C}$. The method of initial rates was used to measure the apparent activation energy of the forward reaction. Reaction rates at four different flow rates (space times) were measured at each temperature. The data were extrapolated to zero space time to approach the limit of zero conversion at which the reverse reaction is negligible. These initial reaction rates were used to determine the apparent activation energy of the forward WGS reaction on these catalysts.

\section{Results and Discussion}

\subsection{BET surface area}

Table 2 shows the BET surface areas obtained by nitrogen physisorption of both the unreduced (fresh) catalysts and the used catalysts exposed to WGS reaction conditions for $100 \mathrm{~h}$ at $400^{\circ} \mathrm{C}$, followed by $16 \mathrm{~h}$ at $500^{\circ} \mathrm{C}$.

The surface areas of the catalysts dropped significantly after use due to sintering $[1,9,10]$. Comparing $88 \mathrm{Fe}-8 \mathrm{Cr}-4 \mathrm{Cu}$ with $88 \mathrm{Fe}-8 \mathrm{Al}-4 \mathrm{Cu}$ before reduction and use, they 
have similar surface areas (around $160 \mathrm{~m}^{2} / \mathrm{g}$ ), but after use, the Fe-Cr-Cu catalyst has $\sim 33 \%$ higher surface area than Fe-Al-Cu (19.5 m²/g vs. $\left.14.9 \mathrm{~m}^{2} / \mathrm{g}\right)$, showing that alumina-containing catalyst (with no chromia) has lower thermal stability. This is consistent with the result reported by Liu et al. [14] that alumina could enhance catalyst stability to some extent, but was not as efficient as chromia and is the reason commercial catalysts contain chromia instead of alumina for stability.

When alumina was combined with chromia, the surface area after use increased in the order $83 \mathrm{Fe}-5 \mathrm{Al}-8 \mathrm{Cr}-4 \mathrm{Cu}$, 78Fe-10Al-8Cr-4Cu, 73Fe-15Al-8Cr-4Cu. After reaching maxima for 78Fe-10Al-8Cr-4Cu (fresh) and 73Fe-15Al-8Cr-4Cu (used), the surface area of both the used and unused catalyst 68Fe-20Al-8Cr-4Cu decreased significantly. A value of around $15 \mathrm{wt} \%$ alumina enhances the used catalyst surface areas apparently by interaction with the traditional stabilizing component, chromia, because this effect of alumina was not observed for the catalyst without chromia. Beyond $15 \mathrm{wt} \%$ alumina addition, the catalysts have smaller surface areas (and lower activity), possibly because of structural collapse during drying $[15,16,17]$.

\subsection{TPR}

Figure 1 shows the result of the TPR- $\mathrm{H}_{2}$ experiments for the unreduced (fresh) alumina-containing catalysts, as well as for the reference catalyst that contains no alumina. The figure shows hydrogen consumption spectra for each catalyst in arbitrary units as a function of reduction temperature. The number shown above the first peak is the temperature at the maximum rate of reduction. This peak, near $320^{\circ} \mathrm{C}$ in each spectra, is attributed to the reduction of $\mathrm{Fe}_{2} \mathrm{O}_{3}$ (hematite) to $\mathrm{Fe}_{3} \mathrm{O}_{4}$ (magnetite) $[9,12,18]$. The broad, higher temperature peak centered around $600-700^{\circ} \mathrm{C}$ is attributed to further 
reduction of $\mathrm{Fe}_{3} \mathrm{O}_{4}$ to $\mathrm{FeO}[12,18,19]$. The peak attributed to the reduction of $\mathrm{Cr}^{6+}$ to $\mathrm{Cr}^{3+}$ (expected near $\left.225^{\circ} \mathrm{C}\right)[18]$ and twin peaks associated with reduction of $\mathrm{Cu}^{2+}$ to $\mathrm{Cu}^{0}$ (expected around $150^{\circ} \mathrm{C}$ ) [18] were not observed, which suggests good dispersion of chromia and copper oxides in the structure [6] broadened the peaks and caused them to be below the detection limit of the apparatus. The low concentrations ( $4 \mathrm{wt} \%$ ) of $\mathrm{CuO}$ in the calcined catalyst also contribute to the difficulty in detecting its reduction peak. The other possible explanation for the absence of these peaks, which is limited or no reduction of these compounds, is unlikely because $\mathrm{CuO}$ and $\mathrm{Cr}_{2} \mathrm{O}_{3}$ are known to reduce at these conditions [18].

In the series the catalysts containing both chromia and alumina, the low temperature reduction peak for the catalyst containing $10 \mathrm{wt} \% \mathrm{Al}_{2} \mathrm{O}_{3}$ is closest to the temperature reported for conventional Fe-Cr-Cu-O catalysts $\left(310^{\circ} \mathrm{C}\right.$ vs $\left.311^{\circ} \mathrm{C}\right)[18]$. Although the other TPR maxima in this series of catalysts occur at higher temperatures compared to the reference catalyst, alumina addition to the catalysts with chromia produces a broad lower temperature shoulder leading up to the maxima. This shoulder is pronounced in the catalysts with 10 and $15 \mathrm{wt} \%$ alumina and indicates an increased quantity of material reducible below $311^{\circ} \mathrm{C}$ that favorably impacts WGS reaction rates because these two catalysts display the highest activity in this series of catalysts (see Section 3.4). The catalysts containing 10 and $15 \mathrm{wt} \%$ alumina also have the lowest peak maxima temperature of the catalysts containing both alumina and chromia.

\subsection{EPMA/SEM results}

EPMA/SEM was used to determine the chemical composition of the catalysts. The results are shown in Table 3. Previous research has shown that similar oxidized 
catalysts contain $\mathrm{Fe}_{2} \mathrm{O}_{3}$ and $\mathrm{Cr}_{2} \mathrm{O}_{3}$ as the predominant oxides [2]. Generally, XRD has not been useful in identifying separate $\mathrm{CuO}$ and $\mathrm{Al}_{2} \mathrm{O}_{3}$ phases $[9,14]$, but the presence of these compounds, as well as $\mathrm{Na}_{2} \mathrm{O}$, have been assumed to interpret the EPMA data in Table 3. The first value in each column shows the target synthesis composition, while the number following in parentheses is the experimentally determined value from EPMA, after converting the measured atomic compositions to the proportional weight $\%$ of the corresponding oxides. The measured values for $\mathrm{Fe}, \mathrm{Cr}, \mathrm{Al}$, and $\mathrm{Cu}$ are all slightly less than the target values because of some residual sodium content. The sodium oxide concentration in each catalyst prepared by $\mathrm{NaOH}$ titration ranged from $\sim 2$ to $4 \mathrm{wt} \%$, despite triple-rinsing with deionized water during filtration to remove the dissolved ions. Quadro et al. [10] reported a similar amount of sodium in similar catalysts precipitated with $\mathrm{NaOH}$. The sodium content did not appear to have a negative long-term effect on catalyst performance, as discussed later in Section 3.4.

Figures 2(a) to 2(d) show the SEM images obtained during the EPMA analysis on the 73Fe-15Al-8Cr-4Cu sample. These representative figures respectively highlight the Fe, $\mathrm{Al}, \mathrm{Cr}$, and $\mathrm{Cu}$ distribution in the unreduced and unused (fresh) $73 \mathrm{Fe}-15 \mathrm{Al}-8 \mathrm{Cr}-4 \mathrm{Cu}$ catalyst after calcination. The images show that $\mathrm{Fe}, \mathrm{Al}, \mathrm{Cr}$, and $\mathrm{Cu}$ are distributed fairly evenly in the catalyst particles, although the Cu shows some agglomeration, as indicated by the bright islands visible in some areas of the particles.

\subsection{Kinetic results}

\subsubsection{Impact of alumina addition}

One catalyst in which alumina completely replaced chromia was synthesized to investigate the relative effects of these two components in the magnetite-based high 
temperature WGS catalysts. The catalyst without chromia was compared with a typical high temperature WGS catalyst prepared with 88 wt $\% \mathrm{Fe}_{2} \mathrm{O}_{3}-8$ wt $\% \mathrm{Cr}_{2} \mathrm{O}_{3}-4$ wt $\% \mathrm{CuO}$ (88Fe-8Cr-4Cu). This fresh catalyst had a slightly smaller initial surface area $\left(158 \mathrm{~m}^{2} / \mathrm{g}\right.$ vs. $\left.166 \mathrm{~m}^{2} / \mathrm{g}\right)$ and a significantly smaller final surface area after use $\left(14.9 \mathrm{~m}^{2} / \mathrm{g}\right.$ vs 19.5 $\mathrm{m}^{2} / \mathrm{g}$ ) compared with chromia-containing catalyst. The rates of both catalysts under WGS conditions during an extended 120 h experiment are shown in Figure 3. The y axis is the specific reaction rate (rate of CO converted (mol/s) per gram of catalyst), while the $\mathrm{x}$ axis is the runtime of the experiment.

This experiment confirmed the previous result of Araujo and Carmo Rangel [9] that alumina cannot effectively replace chromia in these magnetite-based catalysts. Therefore alumina was included in addition to a base amount of chromia in a series of catalysts (i.e., the alumina was added at the expense of the iron content in the catalyst in 5 wt\% increments up to $20 \mathrm{wt} \%$ alumina). Each catalyst was tested under the same conditions as described for Figure 3.

The activity results for these catalysts are shown in Figure 4, along with the reference catalyst that contained no alumina. The catalyst with $5 \mathrm{wt} \%$ alumina (the triangular data points in Figure 4) produced slightly higher rates relative to the catalyst with only alumina (shown in Figure 3), but was worse than the reference catalyst with chromia but no added alumina (the diamond data points in Figure 4). Although the 5 wt\% alumina catalyst initial surface area was $140 \mathrm{~m}^{2} / \mathrm{g}$ compared with $166 \mathrm{~m}^{2} / \mathrm{g}$ for the catalyst with no alumina, the surface area of the used catalyst, tested under the same conditions, was $22.5 \mathrm{~m}^{2} / \mathrm{g}$ compared with $19.5 \mathrm{~m}^{2} / \mathrm{g}$, which shows that alumina provides 
higher thermal stability through increased resistance to sintering $[9,14]$. The rate at the end of the experiment was similar for both catalysts.

In Figure 4, the WGS rate of the catalysts decreased in the order: 73Fe-15Al-8Cr$4 \mathrm{Cu}>78 \mathrm{Fe}-10 \mathrm{Al}-8 \mathrm{Cr}-4 \mathrm{Cu}>88 \mathrm{Fe}-8 \mathrm{Cr}-4 \mathrm{Cu}>83 \mathrm{Fe}-5 \mathrm{Al}-8 \mathrm{Cr}-4 \mathrm{Cu}>88 \mathrm{Fe}-8 \mathrm{Al}-4 \mathrm{Cu}>$ $68 \mathrm{Fe}-20 \mathrm{Al}-8 \mathrm{Cr}-4 \mathrm{Cu}$, which is approximately in the order of their surface area (see Table 2). High temperature WGS reaction occurs on the surfaces of iron oxide (magnetite) domains [1]. Therefore, higher surface areas make more active sites available for the water gas shift reaction, which produces higher catalytic activity. At the end of the experiment, the catalyst that produced the highest rates and had the highest thermal stability, as determined by its surface area after use, contained $15 \mathrm{wt} \%$ alumina.

Up to a value of approximately $15 \mathrm{wt} \%$ alumina addition at the expense of the active iron compound, alumina enhances the used catalyst surface areas apparently by interaction with the traditional stabilizing component, chromia. Beyond $15 \mathrm{wt} \%$ alumina addition, the catalysts have smaller surface areas, possibly because of structural collapse due to higher aluminum hydroxide content that might increase the fragility of the three dimensional structures generated during drying $[15,16,17]$. Another factor in the decreased activity is the reduction in iron oxide content, which is the active phase [1, 2]. However, this loss of iron content is counterbalanced by the synergetic activity of the added alumina for the catalysts containing 10 and $15 \mathrm{wt} \%$, since the rate for both of these catalysts increases relative to the other catalysts that contain more iron. This effect is not merely a simple increase in surface area, as the rate increases exceed the proportional increase in surface area. This observation clearly shows that the loss of iron is not by itself responsible for the poor performance of the catalyst with $20 \mathrm{wt} \%$ alumina. The 
formation of aluminate compounds with the other catalyst components [20] that appear to be inactive for WGS reactions is also a possible explanation for the observed decrease in activity for the $20 \mathrm{wt} \%$ alumina catalyst.

This sharp decrease in rate for the catalyst with $20 \mathrm{wt} \%$ alumina was investigated through two experiments with catalysts containing larger amounts (50 wt\%) of alumina with nominal compositions of $43 \mathrm{Fe}-50 \mathrm{Al}-5 \mathrm{Cr}-2 \mathrm{Cu}$. One was prepared as a mechanical mixture of the most active catalyst (73Fe-15Al-8Cr-4Cu) with sufficient $\gamma$-alumina to produce a physical mixture with 50 total wt $\% \mathrm{Al}_{2} \mathrm{O}_{3}$, identified as $43 \mathrm{Fe}-50 \mathrm{Al}-5 \mathrm{Cr}$ $2 \mathrm{Cu}(\mathrm{m})$. The other was prepared by coprecipitation with a nominal composition of 50 wt\% alumina (43Fe-50Al-5Cr-2Cu).

Both catalysts were tested kinetically under the same water gas shift conditions as the other catalysts. The results of these two experiments are illustrated in Figure 5, along with the 73Fe-15Al-8Cr-4Cu catalyst for comparison. Although the catalyst prepared by coprecipitation (triangles, Figure 5) has higher initial activity compared to the physical mixture catalyst (filled circles, Figure 5), it exhibits low thermal stability and rapid deactivation, possibly due to formation of $\mathrm{FeO}-\mathrm{Al}_{2} \mathrm{O}_{3}$ iron aluminate [20]. Compared to the 73Fe-15Al-8Cr-4Cu catalyst (open circles, Figure 5) used to make the physical mixture, the rate produced by the physical mixture is roughly $40 \%$ lower, consistent with the amount of inert alumina added, as experiments with pure alumina produced no detectable reaction. The physical mixture has higher activity and thermal stability than the the co-precipitated catalyst with $50 \mathrm{wt} \%$ alumina, which suggests that an iron aluminate compound only forms to an appreciable extent when the components are in atomic proximity, as expected during the coprecipitation synthesis. The catalysts appear 
to be stable during simple interfacial contact with alumina, but not under mixing at an atomic or very small crystallite scales.

Although XRD and SEM data on these catalyst samples were desirable, unfortunately they are unavailable (see endnote), but literature results can be used to interpret the data. The effect of alumina addition to iron oxide-chromia based catalysts can be interpreted based on surface and bulk diffusion of atoms and ions in solids, correlated to the Tammann and Huttig temperatures [8]. The Tammann temperature $\left(\mathrm{T}_{\mathrm{T}}\right)$ is conventionally defined as $0.5 \mathrm{~T}_{\mathrm{m}}$, where $\mathrm{T}_{\mathrm{m}}$ is the absolute melting point of the material At $\mathrm{T}_{\mathrm{T}}$, ions within the bulk of the solid are generally considered to be sufficiently mobile for bulk diffusion. The Huttig temperature $\left(T_{H}\right)$ is conventionally defined as $0.3 T_{m}$, at which surface species have sufficient mobility to begin to agglomerate and sinter.

The Tammann temperatures for the pure oxides $[8,20]$ are $~ 1302 \mathrm{~K}\left(1029^{\circ} \mathrm{C}\right)$ for $\mathrm{Cr}_{2} \mathrm{O}_{3}, \sim 935 \mathrm{~K}\left(662^{\circ} \mathrm{C}\right)$ for $\mathrm{Fe}_{3} \mathrm{O}_{4}$, and $\sim 1152 \mathrm{~K}\left(879^{\circ} \mathrm{C}\right)$ for $\mathrm{Al}_{2} \mathrm{O}_{3}$, which are all above the reaction temperature of $350-500^{\circ} \mathrm{C}$. This likely explains why the mechanically mixed catalyst showed good thermal stability, as no bulk diffusion is expected.

The Huttig temperatures for the same oxides $[8,20]$ are $~ 868 \mathrm{~K}\left(595^{\circ} \mathrm{C}\right)$ for $\mathrm{Cr}_{2} \mathrm{O}_{3}, \sim 623 \mathrm{~K}\left(350^{\circ} \mathrm{C}\right)$ for $\mathrm{Fe}_{3} \mathrm{O}_{4}$, and $\sim 768 \mathrm{~K}\left(495^{\circ} \mathrm{C}\right)$ for $\mathrm{Al}_{2} \mathrm{O}_{3}$. Therefore, iron will be the most mobile surface species at the reaction temperatures of this study $\left(350-500^{\circ} \mathrm{C}\right)$. Thus, for oxides mixed at an atomic or very small crystallite scales, the catalyst is expected to be less thermally stable compared with the mechanical mixed one. This analysis is complicated by the possibility of solid solution formation [3, 8, 9, 20] because the ionic radii of $\mathrm{Cr}^{3+}(0.0755 \mathrm{~nm})$ and $\mathrm{Al}^{3+} 0.0675 \mathrm{~nm}$ [3] are close to $\mathrm{Fe}^{3+}(0.069 \mathrm{~nm})$ [3]. Examination of the ternary phase diagram for $\mathrm{FeO}-\mathrm{Fe}_{2} \mathrm{O}_{3}-\mathrm{Al}_{2} \mathrm{O}_{3}$ [20] suggests the 
possibility of formation of $\mathrm{FeO}-\mathrm{Al}_{2} \mathrm{O}_{3}$ iron aluminate spinel (hercynite), which is stable below $2053 \mathrm{~K}\left(1780^{\circ} \mathrm{C}\right)$.

Alumina and the possible formation of aluminates apparently act as a physical barrier for the movement of iron, thus reducing the loss of surface area which in the magnetite based catalysts has been shown to occur by sintering $[1,9,10]$. However, alumina contents greater than $\sim 15 \mathrm{wt} \%$ appear to react with the other catalyst components to form compounds that are inactive for WGS.

\subsubsection{Impact of synthesis method on kinetic performance}

Some of the catalysts in this study were prepared by co-precipitation using either $\mathrm{NaOH}$ or $\mathrm{NH}_{4} \mathrm{OH}$ as the titrating agent. The target and actual (determined by EPMA) compositions of the reference catalyst and the catalyst without chromia prepared by the two methods are shown in Table 3. The catalysts prepared by different methods have nearly the same chemical composition, with the exception of the small amount of sodium in the catalysts prepared using $\mathrm{NaOH}$ titration. However, the activity and stability are significantly different.

Catalysts prepared by with $\mathrm{NH}_{4} \mathrm{OH}$ titrations that required $\mathrm{Cu}$ addition during a subsequent incipient wetness impregnation step showed high initial activity, but their deactivation during operation was larger than for the catalysts prepared in a single step by $\mathrm{NaOH}$ titration. For example, the initial rate produced by the $88 \mathrm{Fe}-8 \mathrm{Cr}-4 \mathrm{Cu}$ catalyst was more than double that of the similar catalyst prepared by $\mathrm{NaOH}$ titration (results presented later in Table 8). However, after $100 \mathrm{~h}$ of operation at $400^{\circ} \mathrm{C}$ and $16 \mathrm{~h}$ at $500^{\circ} \mathrm{C}$, the catalyst prepared with $\mathrm{NH}_{4} \mathrm{OH}$ produced only $71 \%$ of the rate of the one prepared with $\mathrm{NaOH}$. By the two-step synthesis when the copper is added in a second 
step, copper is further concentrated near the surface of the catalysts, as shown by the larger amount measured by EPMA (4.5 wt\% versus $3.7 \mathrm{wt} \% \mathrm{CuO}$ for the $88 \mathrm{Fe}-8 \mathrm{Cr}-4 \mathrm{Cu}$ catalysts prepared by $\mathrm{NH}_{4} \mathrm{OH}$ and $\mathrm{NaOH}$ titration, respectively, in Table 3). The 88Fe8Cr-4Cu catalyst prepared by $\mathrm{NH}_{4} \mathrm{OH}$ titration shows high initial activity, but it is prone to sintering during operation. With sintering of the copper, the catalysts lose activity. The copper concentration from EPMA after WGS operation for the $88 \mathrm{Fe}-8 \mathrm{Cr}-4 \mathrm{Cu}$ catalysts at 9 different points on the surface is shown in Table 4. Consistent with the EMPA data in Table 3, the multiple-location data in Table 4 show that the average copper concentrations are $22 \%$ larger in the $\mathrm{NH}_{4} \mathrm{OH}$ titrated catalysts than the $\mathrm{NaOH}$ titrated catalysts, which suggests that formation of larger copper crystallites with proportionally fewer accessible surface atoms are responsible for the rapid rate decline on the $\mathrm{NaOH}$ titrated catalysts.

The data in Table 4 also show that the copper in the catalysts prepared by $\mathrm{NH}_{4} \mathrm{OH}$ titration is not evenly distributed after use, which further suggests that the copper particles have agglomerated into large crystallites. The standard deviations of the copper compositions ( 0.20 for the catalyst prepared with $\mathrm{NaOH}$ versus 0.93 for the catalyst prepared with $\mathrm{NH}_{4} \mathrm{OH}$ ) indicate that there is much larger variability among the copper concentrations for the catalyst prepared with $\mathrm{NH}_{4} \mathrm{OH}$, which is consistent with sintering to form some large copper particles at the expense of other areas of the surface. Thus, some areas of the surface have high concentrations of large copper crystallites, while other areas of the surface are depleted in copper. A catalyst with less exposed copper surface area, due to agglomeration into larger copper particles, is expected to produce lower WGS reaction rates, which is consistent with the observed results. 


\subsection{Reaction temperature sensitivity: activation energies}

WGS conversions for the series of alumina-containing catalysts (with $20 \mathrm{wt} \%$ or less alumina) at $350^{\circ} \mathrm{C}, 375^{\circ} \mathrm{C}, 400^{\circ} \mathrm{C}$, and $425^{\circ} \mathrm{C}$ are shown in Table 5 and in Figure 6 . Also shown in Figure 6 is the calculated value of the equilibrium conversion at the reaction conditions. The rates of all catalysts increased with increasing temperature, consistent with an Arrhenius-type dependence. Cinchen et al. [21] measured 8.5 mm diameter HT-WGS industrial pellets and observed diffusion limitations which influenced the measurements. For smaller particles, Rhodes and Hutchings [6] found that activation energy was independent of particle size for particles between $100 \mu \mathrm{m}$ and $1000 \mu \mathrm{m}$, suggesting that mass transfer and diffusion are not limiting for these small particles at reaction conditions similar to those applied in the experiments presented here. Consistent with these reported results, diffusional limitations were not observed for particles with diameters of $125-250 \mu \mathrm{m}$ used in the present study, which permitted the measurement of apparent activation energies. Arrhenius plots for the HT water gas shift catalysts are shown in Figure 7, which contains data for initial WGS reaction rates at zero space time. The activation energies determined from the data in Figure 7 are summarized in Table 6. All catalysts with alumina have lower apparent activation energies values compared with the value of $90.5 \mathrm{~kJ} / \mathrm{mol}$ obtained for the reference catalyst, $88 \mathrm{Fe}-8 \mathrm{Cr}-4 \mathrm{Cu}$. The decrease in the value of activation energies with increasing alumina addition suggests that alumina plays more than merely as a textural support that increases surface area, but is actually involved in the catalysis. The modification of the catalysis could be due to an electronic modification of the iron domains, making them more reducible, as suggested by the TPR results (see Figure 1), and consistent with some reports that have suggested that the WGS 
mechanism on iron-based catalysts proceeds via an oxidation-reduction cycle [1, 11, 14]. The lowest absolute value of activation energy $\left(\mathrm{E}_{\mathrm{A}}=65.9 \mathrm{~kJ} / \mathrm{mol}\right)$ obtained for $68 \mathrm{Fe}-$ 20Al-8Cr-4Cu appears to be offset by the lower iron oxide concentration, by the presumed loss of some magnetite to formation of inactive compounds such as iron aluminates, and by the significant loss of surface area during reaction (as only $\sim 10 \mathrm{~m}^{2} / \mathrm{g}$ remained after use, see Table 2). The most active catalyst, $78 \mathrm{Fe}-15 \mathrm{Al}-8 \mathrm{Cr}-4 \mathrm{Cu}$, has a comparable activation energy $\left(\mathrm{E}_{\mathrm{A}}=68.6 \mathrm{~kJ} / \mathrm{mol}\right)$, a larger iron content, and the highest surface area $\left(38 \mathrm{~m}^{2} / \mathrm{g}\right)$ after use.

The activation energy measurements, which involved varying the reaction temperature in the range $350-425^{\circ} \mathrm{C}$, were performed after $50 \mathrm{~h}$ of WGS reaction at $400^{\circ} \mathrm{C}$. After these experiments, the rate was again measured at $400^{\circ} \mathrm{C}$ and compared with the rate at $400^{\circ} \mathrm{C}$ after $50 \mathrm{~h}$. No significant decrease in catalytic activity was observed over the time scale of the activation energy experiments. Therefore, the presented activation energy results were not significantly influenced by deactivation.

\subsection{Catalyst stability}

\subsubsection{Resistance to over-reduction}

The catalytic activity of the series of alumina-containing catalysts (with $20 \mathrm{wt} \%$ or less alumina) at $\mathrm{H}_{2} \mathrm{O}: \mathrm{CO}$ of 2 is given in Table 7. The same trends are observed as described previously for the catalysts at $\mathrm{H}_{2} \mathrm{O}: \mathrm{CO}$ of 3 . The GC column used in these experiments is capable of methane separation. No methane was detected during any experiment. Therefore, no detectable methanation reaction (which is catalyzed by metallic iron [1]) occurred, which indicates these catalysts are not susceptible to overreduction to metallic iron. 


\subsubsection{Thermal stability}

The catalysts were tested for $100 \mathrm{~h}$ at $400^{\circ} \mathrm{C}$, followed by a $16 \mathrm{~h}$ period at $500^{\circ} \mathrm{C}$ to simulate a longer use, followed by a final reaction period at $400^{\circ} \mathrm{C}$ to compare with the rates at $400^{\circ} \mathrm{C}$. When exposed to the $500^{\circ} \mathrm{C}$ reaction temperature, the catalysts deactivated rapidly as shown in Figures 4 and 5 and quantified in Table 8, which shows these relative rates for the series of alumina-containing catalysts.

The data in Table 8 confirm that 73Fe-15Al-8Cr-4Cu catalyst produced the highest final rate, indicating that it had the highest thermal stability after 16 hours of operation at $500^{\circ} \mathrm{C}$, retaining approximately $70 \%$ of the activity it had at $100 \mathrm{~h}$. This compares to less than $67 \%$ the next most stable catalyst (83Fe-5Al-8Cr-4Cu). Also, this rate is nearly 2 times higher than the reference catalyst (88Fe-8Cr-4Cu) prepared by $\mathrm{NaOH}$ titration, which highlights the thermal stability provided by addition of small amounts of alumina.

\section{Conclusions}

Alumina addition to conventional high temperature water gas shift catalysts at concentrations of approximately $15 \mathrm{wt} \%$ increases CO conversion rates and increases thermal stability. If the alumina replaces the chromia content of the catalyst, the surface area after use is only $74 \%$ of the surface area of the comparable Fe-Cr-Cu catalyst. Hence, alumina alone cannot effectively stabilize $\mathrm{Fe}_{3} \mathrm{O}_{4}$.

When alumina is combined with chromia, varying effects were observed on the HT water gas shift catalysts. For the fresh unreduced catalysts, catalysts with both chromia and 10-15 wt\% alumina have high fresh surface areas (over $200 \mathrm{~m}^{2} / \mathrm{g}$ ) that are 20-30\% higher than the catalyst without alumina. The surface area increase is larger than 
the proportional effect expected for the small amounts of alumina added. This suggests that the added alumina has an added structural effect on the other catalyst components. After use, these two catalysts retain higher surface areas (33.4 m²/g and $\left.38.4 \mathrm{~m}^{2} / \mathrm{g}\right)$ compared to the other catalysts. Even the catalyst with the least amount of alumina, 83Fe-5Al-8Cr-4Cu, retained a surface area of $22.5 \mathrm{~m}^{2} / \mathrm{g}$ after use, which is higher than the reference Fe-Cr-Cu catalyst at $19.5 \mathrm{~m}^{2} / \mathrm{g}$. Thus, alumina in Fe-Al-Cr-Cu catalysts significantly increase surface areas, especially for the used catalysts, indicating that thermal stability is also improved.

In the series of alumina-containing HT-WGS catalysts in this study, the optimum quantity of alumina addition is $\sim 15 \mathrm{wt} \%$ (73Fe-15Al-8Cr-4Cu). This catalyst produced a CO conversion rate that was $73.8 \%$ larger than the reference catalyst with no alumina (88Fe-8Cr-4Cu) at similar reaction conditions.

\section{Acknowledgements}

The authors wish to thank the Department of Energy National Energy Technology Laboratory (DE-FC26-05NT42454) and the University of Wyoming School of Energy Resources for financial support and Dr. Susan Swapp for performing the EMPA/SEM analysis.

\section{Endnote}

During a laboratory move, all catalyst samples, both fresh and used, were inadvertently discarded by a third party before desired additional XRD and SEM characterizations could be performed. 


\section{References}

[1] C. Rhodes, G. J. Hutchings, A. M. Ward, Catal. Today 23 (1995) 43-58

[2] H. Topsoe, M. Boudart, J. Catal. 31 (1973) 346-359

[3] S. Natesakhawat, X. Wang, L. Zhang, U S. Ozkan, J. Mol. Catal. A: Chem. 260 (2006) 82-94

[4] P. Kappen, J. Grunwaldt, B. S. Hammershøi, L. Troger, B. S. Clausen, J. Catal. 198 (2001) 56-65

[5] M. V. Twigg, Catalyst Handbook, $2^{\text {nd }}$ edition, Wolfe Publishing, London, 1989

[6] C. Rhodes, G. J. Hutchings, Phys. Chem. Chem. Phys. 5 (2003) 2719-2723

[7] Chinchen, G. C., R. H. Logan, M. S. Spencer, Appl. Catal. 12 (1984) 89-96

[8] M. A. Edwards, D. M. Whittle, C. Rhodes, A. M. Ward, D. Rohan, M. D. Shannon,

G. J. Hutchings, C. J. Kiely, Phys. Chem. Chem. Phys. 4 (2002) 3902-3908

[9] G. C. de Araujo, M. do Carmo Rangel, Catal. Today, 62 (2000) 201-207

[10] E. B. Quadro, M. de Lourdes Ribeiro Dias, A. M. M. Amorim, M. do Carmo Rangel, J. Braz. Chem. Soc., 10 (1999) 51-59

[11] D.G. Rethwisch, J.A. Dumesic Appl. Catal. 21 (1986) 97-109

[12] J. L. R. Costa, G. S. Marchetti, M. do Carmo Rangel, Catal. Today, 77 (2002) 205213

[13] Y. Lei, N. W. Cant, D. L. Trimm, Chem. Eng. J. 114 (2005) 81-85

[14] Q. Liu, W. Ma, R. He, Z. Mu, Catal. Today 106 (2005) 52-56

[15] C. P. Royall, A. M. Donald, Phys. Rev. E 66 (2002) 021406-1-021406-8

[16] H. M. Jennings, J. J. Thomas, J. S. Gevrenov, G. Constantinides, F. J. Ulm, Cem. Concr. Res. 37 (2007) 329-336 
[17] W. Qiu, Y. Kang, Q. Li, Z. Lei, Q. Qin, Appl. Phys. Lett. 92 (2008) 041906-1041906-3

[18] A. Khan, P.G. Smirniotis, J. Mol. Catal. A 280 (2008) 43-51

[19] J. J. Hua, K. Wei, Q. Zheng, X. Lin, Appl. Catal. A 259 (2004) 121-130

[20] E.M. Levin, Phase diagrams for ceramists, American Ceramic Society, Columbus, 1964

[21] G. C. Chinchen, R. H. Logan, M. S. Spencer, Appl. Catal. 12 (1984) 69-88 